\title{
Biofuel as an alternative energy source: How much to give up?
}

Veronica Betancur, Aditi Bhattacharjee, Natalia Gisbert, Mariluz Restrepo, Praveen Sharma ${ }^{i}$

Increasing oil prices have raised some serious global concerns. However, the fact remains that most solutions to tackle the increasing trend in the price of oil are controversial in one way or another. Some of the popular solutions often reduce greenhouse gases at the expense of pushing the poorest deeper into poverty. It is therefore self-evident that the world needs to find a middle path, a harmonious balance between feeding the millions and filling the gas tanks in order to ensure stability for everyone. To achieve this, green fuel alternatives such as biofuels are broadly considered an exciting prospect, which, in turn, has resulted in the market demand for ethanol to increase faster than expected. The existing supply of grain is however unable to meet the challenge of feeding and fuelling the world at the same time. The price of grain is therefore increasing more rapidly than ever especially after America's ethanol expansion program in 2005; recklessly subsidizing the production of ethanol is costing a year's supply of food grains for a person in exchange for filling the fuel tank in one SUV (Buntrock 2007). Such surging food prices are even more likely to affect the underdeveloped and developing countries and thus solution must be found to avoid pushing the poor in these countries to the brink of starvation.

We live and work in a world driven by fossil-fuelled economies. Especially the transport systems of countries round the world are reliant primarily on gasoline derived from oil and thus the situation naturally turns dire when the monthly average price of one barrel of oil 
soars from US\$66.89 in June 2007 to US\$127.57 in June 2008 (OPEC 2008). This monopoly on transportation fuel gives indisputable power to OPEC and other nations that dominate oil ownership and production. However, the producers and consumers of energy rarely take into account the full extent of the negative externalities of fuel production and consumption they impose on the international society and global environment.

A conventional externality diagram, as shown below, helps to better illustrate this situation in the fuel market. The demand curve (D) also depicts marginal private benefit (MPB). The MPC curve shows both the marginal private cost of producing oil, which are the costs incurred by producers as well as the supply curve (S). The marginal social cost (MSC) adds external costs to these private costs and therefore shows the marginal cost incurred by the producer plus the marginal cost imposed on others. Therefore the external costs or negative externalities are represented by the wedge between the MSC and MPC.

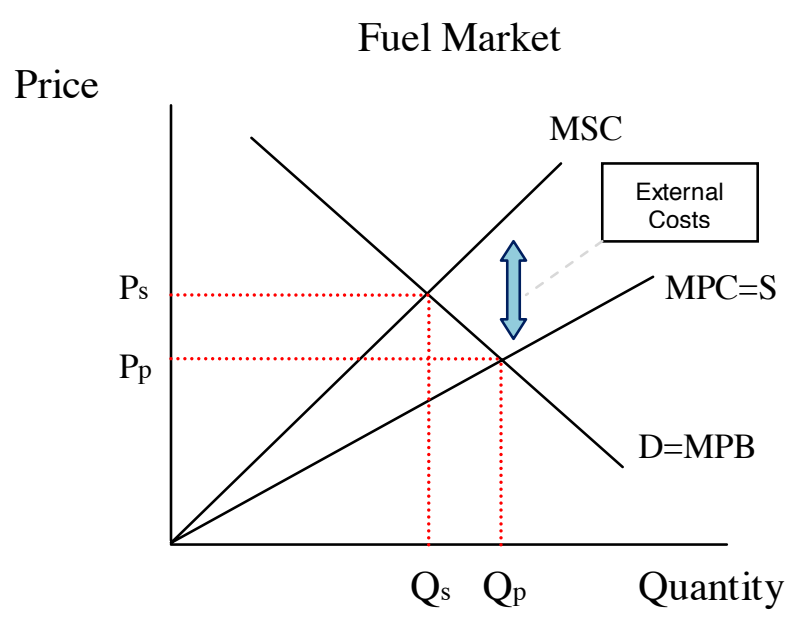


Key negative externalities from the fuel market are manifested in public health and the environment. Several research projects state that air pollution may cause cardiopulmonary diseases that could have premature lethal effects (Michaels 2005). The production and use of fossil fuel energy is considered to be the most important source of greenhouse gas emissions in the world attributable to humans, which then cause air pollution problems such as acid rain and smog resulting in climate change. These are just some examples of negative externalities that are imposed by rational profit seeking market participants on jointly consumed social goods such as the environment simply because the latter lack a set of clear property rights (ExternE 2008).

Ethanol has been seen as a viable fuel right from the beginnings of the automobile itself. It contributes to environment conservation due to greenhouse gas reduction (largely due to high carbon sequestration in its production) and it is considered a possible solution to tackle global warming. However, what are the implications of increasing our reliance on ethanol production? To answer this question it is necessary to understand the ethanol industry. Ethanol is being used in gasoline because of its high octane and relatively cleanburning properties. While ethanol-mixed fuel is used extensively in a number of countries, most notably Brazil, the US is also a major producer of corn-based ethanol. Its production averaged 6.48 billion gallons in 2007, an increase of $32 \%$ over 2006 . The demand averaged 6.84 billion gallons in the same period which generated a shortage of 36 million gallons, in part supplied by sugarcane-based ethanol imported from Brazil. As a result, the capacity to produce ethanol in the US needs to be increased and is projected to grow a further 4 billion gallons in 2008 (Laws 2008). However, to increase this capacity more corn will be needed and more land will be utilized to grow corn. Producers will be able to earn more because of a rise in corn prices. However, this marginal private benefit produces an immense social cost on the related food market through a supply shortfall and rising food prices. Ethanol 
production has contributed to a decline in grain stocks devoted to food, pushing up their price as well as causing a knock on effect on the price of cereal and meat since farm animals are also usually fed with grain. Therefore ethanol is considered a threat to world food supply, the production of which might lead low income countries deeper into poverty. In order to reduce such negative externalities of the fuel and biofuel markets there is a need for a regulating body that motivates the social planner, educates society, aggregates civil society responses and encourages private market initiatives. The overarching problem for the regulator is clear; environmental damage and heath concerns generated from the fuel market can be diminished by the use of biofuels, however the biofuel market itself comes with a string of social costs demonstrated by rising food prices. To counter this situation, the social planner can intervene by promoting alternate means of energy such as nuclear and solar. Similarly, a private response to such a situation may be automobile manufacturers coming up with the discovery of some new technology enabling cars to run on alternate energy sources such as fuel cells. Naturally, even here the regulator faces several either environmentally damaging or highly expensive choices. Solar energy remains expensive to trap for comprehensive domestic and industrial usage. Nuclear power involves uranium mining and hazardous waste disposal issues leading to high social costs in other areas. The crux of the global energy crisis is simple: any energy market response will likely bring some negative externalities. An illustrative example is any effort to reduce the aggregate social costs arising from the biofuel market. Negative externalities of the biofuel market can be reduced if governments decide on the maximum limit of food grains to be utilized for the production of ethanol. At any point in time, governments have to trade-off some food grains, which otherwise would have been used to feed people, in order to produce ethanol. Conventional economic theory would suggest that social efficiency will be reached when governments can encourage production across food and fuel markets such that the ratios of social marginal costs and social marginal benefits in each are equalized. 
The Hecksher-Ohlin theory emphasizes the role of varying relative factor endowments across countries. Production of goods therefore depends on the intensity and type of factors used to produce them. In the case of food and fuel this factor may well just be simplified to a specific type of land. Let us take as an example Country A which is a growing food-rich economy and Country B which is abundant in fuel. An uncomplicated example can therefore be constructed where Country A has a comparative advantage in food production over Country B. Similarly, Country B has an advantage in the production of fuel. Now, Country A could conceivably divert its exported food output to the production of biofuels in order to meet domestic fuel needs due to growth. If it remains unconcerned about the fact that using more food grains to produce biofuels pushes the global price of food higher, it may decide to produce biofuel regardless. However, the world may also include food-poor and fuel-poor countries and environmental and scarcity issues throughout the world could augment the demand for fuel and food, which will then further push prices up for both. Owing to the high switching cost involved in shifting from fossil fuel to biofuel, the demand for petrol remains steady, especially in the short run. Country B will therefore continue concentrating on fuel production and continue charging exorbitant prices to the rest of the world. This leaves a several countries which are food and fuel-poor worse off than before. This thought experiment demonstrates the reckless abandon of the food rich and fuel rich countries pushing certain underdeveloped and developing countries to a most disadvantageous situation. They bear the brunt of rising fuel and food prices. They have to continue the importation of food grains and fuel at ever higher prices leading to burgeoning trade deficits.

However, a possible avenue of escape does exist for these countries that appear to be getting a raw deal since they typically possess an abundance of arable land even if they are often overpopulated. Consequently, fuel and food-poor countries could conceivably take 
advantage of better farming techniques from countries that have a shortage of arable land or where the opportunity cost of such land is on the rise. They could presumably also form a cartel and work towards increasing their agricultural production or they could seek help from the World Bank or IMF. As the developing and under-developed countries become self sufficient in feeding their millions, they can also utilize their excess capacity in supplying the fuel rich countries in exchange for oil and also producing biofuels themselves.

The immediate future looks very promising for biofuels even if the desirability of its rapid development is questionable. However, the high switching costs involved are leaving governments open to different predictions. Any increasing shift from petroleum to ethanol will not only need to involve significant changes from the transportation industry but also all other industries that use oil in their production processes. This means huge costs for governments to facilitate this changeover. Governments can either defer switching over to biofuels or may choose to take action now. In the first case future generations will be at peril. Not taking ownership of the responsibility now may result in increasing the quantum of environmental damages, thus creating a mammoth task for future generations. However completely shifting to fuel substitutes will incur huge expenses for the present societies, which is highly undesirable for any government serving a five year term or a rationally myopic populace. Compromise is likely the answer; the best practice involving spreading out the switching costs over a longer horizon. But that nevertheless involves making crucial decisions and positive changes immediately. This involves adopting environmental reform policies and setting long term goals for reduction of carbon emissions now. Increasing the production of ethanol in smaller quantities may help keep the food prices under control as the market is given the time for a more elastic response to the measures. 


\section{References}

- Buntrock G 2007, “Cheap no more”, The Economist, retrieved 1 June 2008, www.economist.com/displaystory.cfm?story_id $=10250420$

- ExternE 2008, ExternE - Externalities of energy: a research project of the European Commission, ExternE, retrieved 29 May 2008, www.externe.info

- Laws F 2008, "Ethanol production continues to rise; demand outpacing supply", Southwest Farm Press, vol. 35, no. 9, pp. 5-7, retrieved 5 May 2008, Business Source Premier Database.

- Michaels P 2005, Environmental Externalities and Air Pollution, Green Nature, retrieved 29 May 2008, www.greennature.com/article473.html

- OPEC 2008, Opec Basket Price, OPEC, retrieved 30 June 2008, http://www.opec.org/home/basket.aspx

\footnotetext{
'Graduate Students, Deakin Business School, corresponding author's email: aditibhm@gmail.com
} 